\title{
Neural-Activity-Dependent Release of S100B from Astrocytes Enhances Kainate-Induced Gamma Oscillations In Vivo
}

\author{
Seiichi Sakatani, ${ }^{1}$ Akiko Seto-Ohshima, ${ }^{2}$ Yoshiaki Shinohara, ${ }^{1}$ Yasuhiko Yamamoto, ${ }^{3}$ Hiroshi Yamamoto, ${ }^{3}$ \\ Shigeyoshi Itohara, ${ }^{2}$ and Hajime Hirase ${ }^{1}$ \\ ${ }^{1}$ Hirase Research Unit, Neuronal Circuit Mechanisms Research Group, and ${ }^{2}$ Laboratory for Behavioral Genetics, RIKEN Brain Science Institute, Wako, \\ Saitama 351-0198, Japan, ${ }^{3}$ Department of Biochemistry and Molecular Vascular Biology, Kanazawa University Graduate School of Medical Science, \\ Kanazawa 920-0864, Japan
}

\begin{abstract}
$\mathrm{S} 100 \mathrm{~B}$ is the principal calcium-binding protein of astrocytes and known to be secreted to extracellular space. Although secreted S100B has been reported to promote neurite extension and cell survival via its receptor [receptor for advanced glycation end products (RAGE)], effects of extracellular S100B on neural activity have been mostly unexplored. Here, we demonstrate that secreted S100B enhances kainate-induced gamma oscillations. Local infusion of S100B in $S 100 B(-/-)$ mice enhanced hippocampal kainate-induced gamma oscillations in vivo. In a complementary set of experiments, local application of anti-S100B antibody in wild-type mice attenuated the gamma oscillations. Both results indicate that the presence of extracellular S100B enhances the kainate-induced gamma oscillations. In acutely isolated hippocampal slices, kainate application increased S100B secretion in a neural-activity-dependent manner. Further pharmacological experiments revealed that S100B secretion was critically dependent on presynaptic release of neurotransmitter and activation of metabotropic glutamate receptor 3. Moreover, the kainate-induced gamma oscillations were attenuated by the genetic deletion or antibody blockade of RAGE in vivo. These results suggest RAGE activation by S100B enhances the gamma oscillations. Together, we propose a novel pathway of neuron-glia communications-astrocytic release of S100B modulates neural network activity through RAGE activation.
\end{abstract}

Key words: glia; hippocampus; mGluR3; local field potential; seizure; neuron-glia interactions

\section{Introduction}

Astrocytes are an indispensable component of neuron-glia circuitry as they provide maintenance of extracellular space and metabolic support to neurons (Kettenmann and Ransom, 2005). In addition to the supportive roles of astrocytes, it has been hypothesized that astrocytes actively participate in neural processing by releasing neurotransmitters including ATP and glutamate (Newman, 2003; Volterra and Meldolesi, 2005). S100B is an EFhand-type calcium-binding protein predominantly expressed in astrocytes in the mammalian CNS (Zimmer et al., 1995; Sen and Belli, 2007). Although S100B has been reported to function as intracellular calcium sensor (Donato, 2003) or buffer (Xiong et al., 2000), it is also known that S100B is secreted from astrocytes to extracellular space in vitro (Shashoua et al., 1984; Van Eldik

\footnotetext{
Received Aug. 4, 2008; accepted Sept. 13, 2008.

This work was supported by a Grant-in-Aid for Scientific Research on Priority Areas from the Ministry of Education, Culture, Sports, Science, and Technology of Japan (18053026), Human Frontier Science Program (RGY0073/ 2006), and the RIKEN Brain Science Institute intramural research funds. We thank the FANTOM3 Consortium (Carninci et al., 2005) for providing S100B CDNA. We also appreciate Dr. Shogo Endo (Okinawa Institute of Science and Technology, Okinawa, Japan) for his advice on S100B purification. We thank Drs. Norio Takata and Tadaharu Tsumoto for their critical reading of this manuscript and Kazuko Yahagi, Takeshi Kanda, and lori Tomizawa for their technical assistance.

Correspondence should be addressed to either of the following at the same address: Seiichi Sakatani or Hajime Hirase, RIKEN Brain Science Institute, Neuronal Circuit Mechanisms Research Group, Wako-shi, 351-0198, Japan. E-mail: sakatani@brain.riken.jp or hirase@brain.riken.jp.

DOI:10.1523/JNEUROSCI.3693-08.2008

Copyright $\odot 2008$ Society for Neuroscience $\quad$ 0270-6474/08/2810928-09\$15.00/0
}

and Zimmer, 1987). In various neuropathological conditions including Alzheimer's disease, epilepsy, and schizophrenia, increased levels of S100B expression are observed in the serum and CSF (Griffin et al., 1989, 1995; Rothermundt et al., 2004; Schmitt et al., 2005), indicating a potential role of the protein in malfunctioning CNS.

Nanomolar concentrations of S100B can stimulate neural process outgrowth (Kligman and Marshak, 1985) and astrocyte proliferation (Selinfreund et al., 1991), although it can be neurotoxic at micromolar concentrations (Sorci et al., 2004) in culture assays. Whether these observations can be implied in intact brain tissue is not known. S100B is known to act as a ligand for receptors for advanced glycation end products (RAGE) (Hofmann et al., 1999). Activation of RAGE by S100B was demonstrated to stimulate neural outgrowth by activation of Cdc/Rac signaling pathway (Huttunen et al., 1999) and to be neuroprotective via Ras/mitogen-activated protein kinase (Huttunen et al., 2000). In contrast, effects of extracellular S100B on neural activity have been mostly unexplored.

Slice experiments using transgenic and knock-out animals indicate that $\mathrm{S} 100 \mathrm{~B}$ has a role in synaptic plasticity. Behavioral assessments using such animals show that hippocampusdependent memory is affected (Gerlai et al., 1995; Nishiyama et al., 2002). At the neural dynamics level, kainate (KA)-induced hippocampal CA1 gamma oscillations are attenuated in S100B(-/-) mice in vivo (Sakatani et al., 2007); however, the 
A
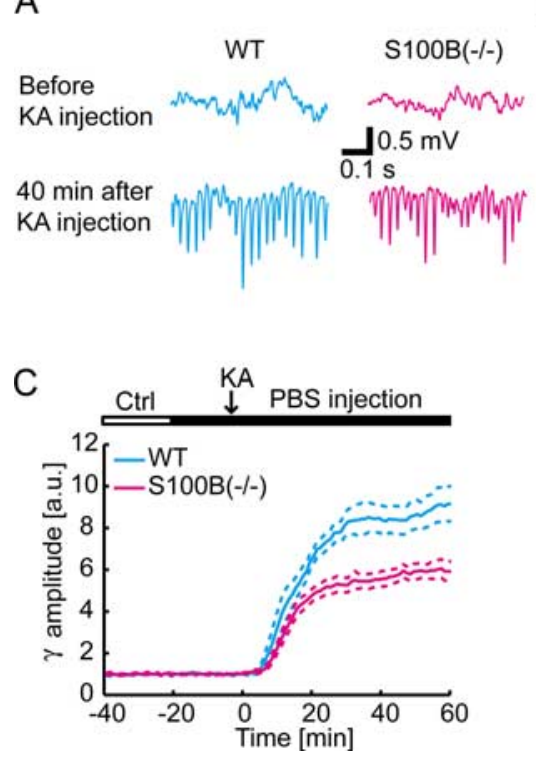

B
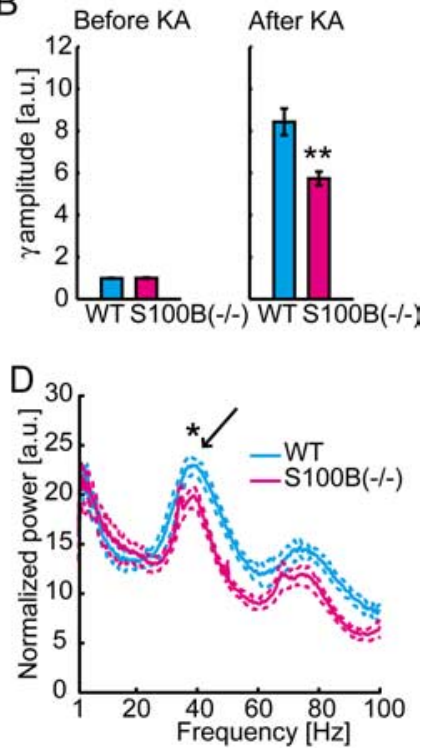

Figure 1. Power of CA1 stratum radiatum KA-induced gamma-band activity injection is attenuated by deletion of S100B. Traces for WT and $S 100 B(-/-)$ are shown in blue and red, respectively. $A$, A representative experiment shows that gamma oscillations in CA1 stratum radiatum after KA injection is smaller in the $5100 B(-/-)$ animal. The traces are local field potential recordings in CA1 stratum radiatum. $\boldsymbol{B}$, Group comparison of the gamma-band $(30-80 \mathrm{~Hz})$ local field potential amplitudes shows similar amplitudes in $0-10$ min before KA injection (left graph; mean \pm SEM; WT, $n=9 ; S 100 B(-/-), n=11 ; p=0.75$ ) but reduced amplitudes in S100B (-/-) animals 40-50 min after KA injection (right graph; mean $\pm \mathrm{SEM}$; $\left.{ }^{* *} p<0.001\right)$. C, Time course of the gamma-band amplitude is plotted for WT and S100B(-/-) animals (mean \pm SEM). For each experiment, the gamma-band amplitude is normalized to the averaged magnitude during control period. $\boldsymbol{D}$, Power spectra from 30 to 50 min after KA injection in WT and S100B (-/-) animals (mean \pm SEM). Note a significant difference $\sim 40 \mathrm{~Hz}\left({ }^{*} p<0.05\right)$. Gamma-band spectral peak is evident (arrow). a.u., Arbitrary units; Ctrl, control (in this and subsequent figures).

underling mechanism has been unclear. Here, we demonstrate that $\mathrm{S100B}$ is released to the extracellular space in a neural and synaptic-activity-dependent manner. Furthermore, we show that extracellular S100B increases the amplitude of the gamma oscillations, and genetic deletion or antibody blockade of RAGE abolishes the effect in live mice. Our results suggest secreted S100B from astrocytes has a neuromodulatory effect through RAGE activation.

\section{Materials and Methods}

Subjects and surgery. Homozygous S100B knock-out mice [S100B(-/-)] of C57BL/6J genetic background were generated as described by Nishiyama et al. (2002). The heterozygous mice that had been backcrossed 18 times with $\mathrm{C} 57 \mathrm{BL} / 6 \mathrm{~J}$ were intercrossed to generate $S 100 B(-/-)$ and control wild types (WTs). The first and second generations from these congenic mice were used in this study. C57BL/6J mice were also used as the control WTs. In some experiments, RAGE(-/-) mice (Myint et al., 2006) were used. Mature male mice of weight range 23-28 g were anesthetized with urethane (1.7 g/kg; U2500; Sigma) and placed in a stereotaxic apparatus. The scalp was surgically removed, and small craniotomies were made at designated stereotaxic coordinates (see below). The body temperature was maintained at $37^{\circ} \mathrm{C}$ throughout the surgery and experiment by a heat pad with feedback temperature control (TR-200; Fine Science Tools). All experimental protocols were approved by the RIKEN Institutional Animal Care and Use Committee.

In vivo physiology. Extracellular recordings with local infusion of biochemical reagents were performed using borosilicate glass electrodes (1B100F-4; World Precision Instruments) and the Multiclamp 700B amplifier (Axon Instruments). The inner tip diameter of the electrode was 2 $\mu \mathrm{m}$. Glass electrode was mounted to an electrode holder used for patchclamp recordings so that air pressure to the electrode could be applied through a pressure-adjustable pneumatic pump (PV-820; World Precision Instruments) to locally infuse the content of the electrode at the tip. Craniotomies of diameter $\sim 1 \mathrm{~mm}$ were made at a stereotaxic coordinate of anterior-posterior (AP) $2.0 \mathrm{~mm}$ and mediallateral (ML) $1.9 \mathrm{~mm}$ on both sides of the skull. Each glass electrode was attached to a fine manipulator of the stereotaxic apparatus and gently progressed through the dura-removed cranial window with an insertion angle of $75^{\circ}$. The CA1 pyramidal cell layer was recognized by the presence of multiunit activity and ripple $(100-180 \mathrm{~Hz})$ oscillations. Recordings at stratum radiatum were obtained at $200 \mu \mathrm{m}$ ventral from the pyramidal cell layer. All electrophysiological signals were digitized with 16-bit resolution and sampled at $32.556 \mathrm{kHz}$ (bandwidth, $\sim 0.1 \mathrm{~Hz}-9 \mathrm{kHz}$ ). For each experiment, $20 \mathrm{~min}$ of control data were acquired. Reagents including PBS, $80-90 \%$ dimeric S100B (10 $\mu \mathrm{M}$ in PBS), nonimmune (control) rabbit IgG (I5006; Sigma-Aldrich), rabbit polyclonal anti-S100B antibody (Product ID 37; Swant), nonimmune (control) mouse $\mathrm{IgG}_{2 \mathrm{a}}$ (PP102; Millipore), mouse monoclonal anti-RAGE antibody (MAB5328; Millipore), nonimmune (control) goat IgG (AB-108-C; R\&D Systems), and goat polyclonal anti-RAGE antibody (AF1179; R\&D Systems) were carefully infused with a pressure of $1.5-3$ psi $(10-20 \mathrm{kPa})$. All the specific antibodies and nonimmune (control) IgGs were infused at a concentration of $0.2 \mathrm{mg} / \mathrm{ml}$. PBS used for local infusion (either with or without S100B) included $1.3 \mathrm{~mm}$ of calcium. S100B was purified as described previously (Nishiyama et al., 2002). The total injection volume in $2 \mathrm{~h}$ of experiment ranged between 90 and $280 \mathrm{nl}$. Twenty minutes after local infusion of reagents, kainate $(1 \mathrm{mg} / \mathrm{ml}$ in physiological saline; 114 00611; Wako Pure Chemical Industries) was administered intraperitoneally at a dosage of $10 \mathrm{mg} / \mathrm{kg}$ to induce gamma oscillations and the following seizures.

Biochemistry. CSF was collected by inserting a fine filamented glass pipette (tip diameter, $\sim 100 \mu \mathrm{m}$ ) to the lateral ventricle (stereotaxic coordinate, AP, $-0.2 \mathrm{~mm}$; ML, $1.1 \mathrm{~mm}$; dorsal-ventral, $1.7-2.1 \mathrm{~mm}$ ) at different time points of the KA seizure experiment. The CSF accumulated in the pipette by the capillary action without extra suction at an approximate rate of $300 \mathrm{nl} / \mathrm{min}$. The collected $5 \mu \mathrm{l} \mathrm{CSF}$ samples were stored at $-80^{\circ} \mathrm{C}$ without any preservatives until further analysis. After 10 times dilution of the sample, quantitative assessment of S100B was made by ELISA using a commercial kit (Sangtec S100 ELISA; DiaSorin). ARVOmx fluorescent plate reader (PerkinElmer) was used to read the absorbance at $450 \mathrm{~nm}$ of ELISA experiments.

Coronal hippocampal slices with $300 \mu \mathrm{m}$ thickness were prepared from postnatal day 21-29 C57BL/6J mice using a microslicer, in accordance with the previous literature (Gloveli et al., 2005) in which gamma oscillations were induced by KA. The slice samples were kept in $33^{\circ} \mathrm{C}$ artificial CSF (aCSF) containing (in $\mathrm{mm}$ ) $113 \mathrm{NaCl}, 2.4 \mathrm{KCl}, 24.9$ $\mathrm{NaHCO}_{3}, 1 \mathrm{NaH}_{2} \mathrm{PO}_{4}, 1 \mathrm{CaCl}_{2}, 1.6 \mathrm{MgSO}_{4}, 27.8 \mathrm{D}$-glucose bubbled with $95 \% \mathrm{O}_{2}, 5 \% \mathrm{CO}_{2}$ for at least $1 \mathrm{~h}$ for recovery. Five slices were used to make a measurement for each experiment. The recovered slices in each chamber were superfused with $500 \mu$ l gassed aCSF that contained the following (in mM): $119 \mathrm{NaCl}, 2.5 \mathrm{KCl}, 26.2 \mathrm{NaHCO}_{3}, 1 \mathrm{NaH}_{2} \mathrm{PO}_{4}, 2.5$ $\mathrm{CaCl}_{2}, 1.3 \mathrm{MgSO}_{4}, 11 \mathrm{D}$-glucose for $30 \mathrm{~min}$. After $30 \mathrm{~min}$ control period, $50 \mu \mathrm{l}$ bath solution was sampled. The slices were then incubated in $500 \mu \mathrm{l}$ $\mathrm{KA}(400 \mathrm{~nm})$ containing aCSF for another $30 \mathrm{~min}$. In some experiments, pharmacological reagents such as $1 \mu \mathrm{M}$ tetrodotoxin (TTX), $100 \mu \mathrm{M}$ $N$-acetyl- $\beta$-asp-glu ( $\beta$ NAAG), $100 \mu \mathrm{M}$ cadmium chloride (Cd), $1 \mu \mathrm{M}$ bafilomycin A1 (Baf), and $100 \mu \mathrm{M}$ Gap 26 were coincubated with KA. Baf was incubated for $2 \mathrm{~h}$ before the incubation of KA (Zhou et al., 2000). After the incubation, $50 \mu \mathrm{l}$ bath solution was also sampled, and the $\mathrm{S} 100 \mathrm{~B}$ concentration in the bath solution was measured by the ELISA kit. The hippocampal slices were completely dissolved by $0.5 \mathrm{ml}$ RIPA buffer $(20$ 
mм Tris- $\mathrm{HCl}, \mathrm{pH} 7.5,150 \mathrm{~mm} \mathrm{NaCl}, 2 \mathrm{~mm}$ EDTA, $0.1 \%$ SDS, $1 \%$ Triton $\mathrm{X}-100)$ with $1 \times$ Protease Inhibitor Cocktail (Complete, EDTAfree; Roche Diagnostics) at $4^{\circ} \mathrm{C}$ for overnight. The total amount of protein of five slices was measured by using the BCA method (BCA Protein Assay Kit; Pierce). Gap 26 was purchased from Tocris (catalog \#1950). $\beta$ NAAG was purchased from Sigma-Aldrich (A9436). All other chemicals were purchased from Wako Pure Chemical Industries.

Primary hippocampal astrocyte cultures were prepared from Sprague Dawley rats of age postnatal day $2-4$. The hippocampi were carefully dissected in 10 mM HEPES buffered HBSS (084-08345; Wako). The tissue was cut into small pieces and digested in HEPES-buffered HBSS containing $0.25 \%$ trypsin (203-11302; Wako) and 0.4\% DNase I (DN-25; Sigma) for $15 \mathrm{~min}$ at $37^{\circ} \mathrm{C}$. After digestion, the cells were mildly triturated by pipetting, centrifuged in DMEM supplemented with $10 \%$ fetal bovine serum (FBS), and resuspended in $3 \mathrm{ml}$ DMEM with 10\% FBS and penicillin and streptomycin (15070-063; Invitrogen). The cell mixture was then filtered through $40 \mu \mathrm{m}$ cell strainer (352340; BD Falcon), and the cells were plated at a density of $1.0-3.0 \times 10^{5}$ cells/well on 60 mm culture dishes. We used $80-90 \%$ confluent cultures in 14-21 d in vitro for experiments.

To evaluate the secretion of S100B from the astrocyte primary culture, the culture was gently washed with DMEM (15070-063; Invitrogen) three times and preincubated in DMEM for $2 \mathrm{~h}$. The culture was then incubated in $1 \mathrm{ml}$ of fresh DMEM for $30 \mathrm{~min}$, and bath solution was sampled as control. Next, the culture was incubated in $50 \mu \mathrm{M}$ L-glutamate (Nacalai Tesque) in $1 \mathrm{ml}$ DMEM for another 30 min, and $50 \mu \mathrm{l}$ bath solution was sampled. S100B concentration in the bath solution was measured by the ELISA kit.

Data analysis. Local field potential data were analyzed by custom-made software using MATLAB (MathWorks) running on a linuxbased computer. Raw wideband recording data were first downsampled to $1.25 \mathrm{kHz}$, and the power spectrum transition was computed by the Fourier transform for each contiguous time bin of 1 min over the entire recording. Gamma amplitude for each time bin was computed by taking the square root of the power spectrum of frequency range between $30-80 \mathrm{~Hz}$. In some rare instances, harmonic noise of the power supply was digitally attenuated. All bar graphs in the figures are presented in mean \pm SEM, and the other measured values in the text are presented in mean $\pm \mathrm{SD}$. Two-tailed $t$ tests were used for comparisons of two population means, unless otherwise noted.

\section{Results}

\section{Amplitude enhancement of kainate-induced gamma oscillations by $\mathrm{S100B}$}

Neural activity at gamma frequency range $(30-80 \mathrm{~Hz})$ is important for cognitive functions, learning, and memory in the cortex and hippocampus (Gray et al., 1989; Engel and Singer, 2001; Montgomery and Buzsáki, 2007). In rodent hippocampus, gamma oscillations of similar frequency range can be induced by KA in vitro and in vivo [for review, see Bartos et al. (2007)]. KA-induced gamma oscillations are generated in CA3 region

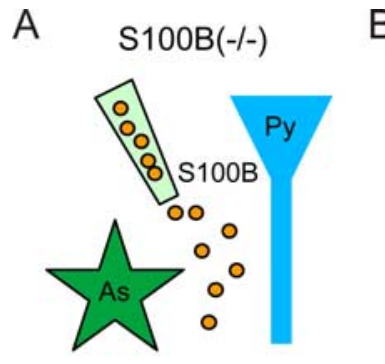

B
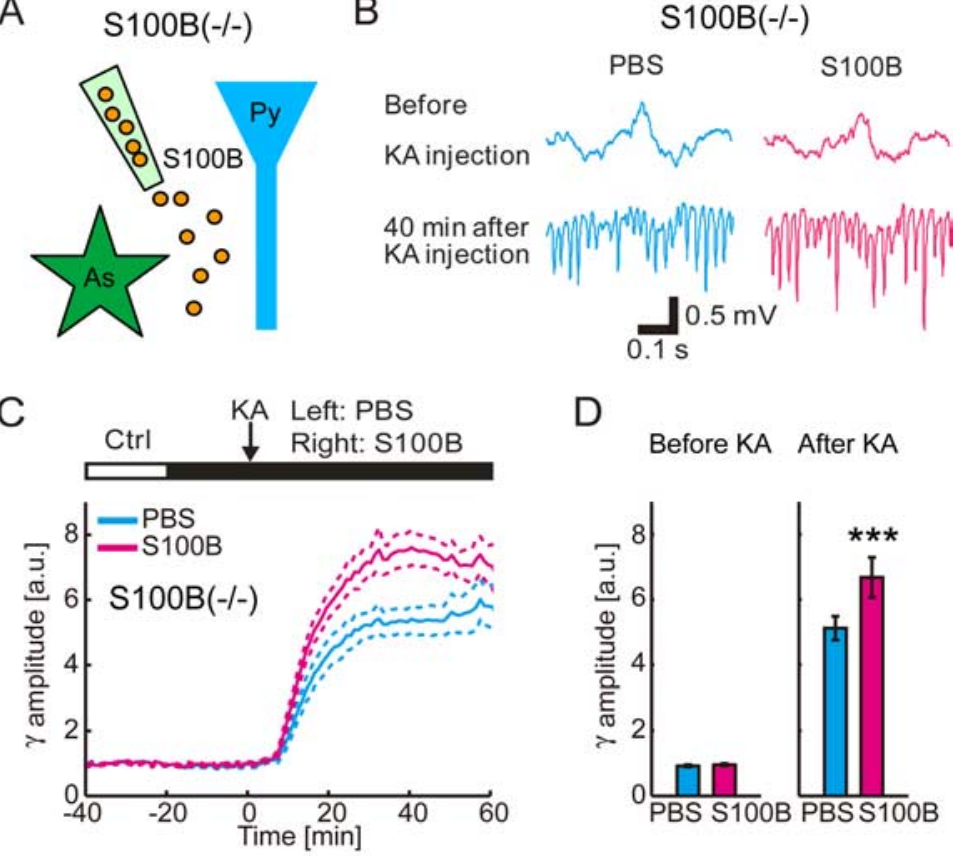

D Before KA After KA

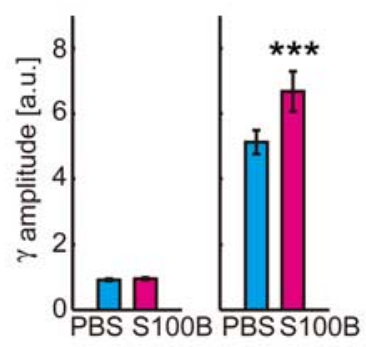

$\mathrm{F}$

Before KA After KA

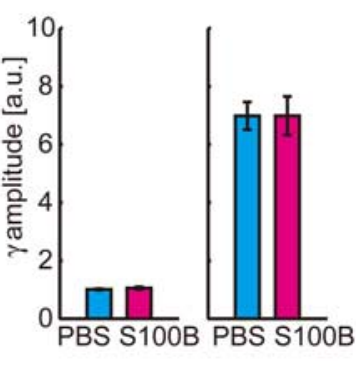

Figure 2. Exogenous extracellular S100B enhances KA-induced gamma oscillations in S100B(-/-) mice. $A$, Schematic diagram of the experiment. $\mathrm{S100B}$ (orange particle) is injected by a pipette in $\mathrm{S100B}(-/-)$ mice. As, Astrocyte; Py, pyramidal cell. $B$, Representative traces of field potential recording before and $40 \mathrm{~min}$ after $\mathrm{KA}$ injection $(10 \mathrm{mg} / \mathrm{kg}$, i.p.) shows that gamma (10 Note that local infusion of $S 100 B$ significantly increases gamma-band amplitude from 10 to 60 min after KA 0 -10 ( (right; mean $\pm \mathrm{SEM}$; *** $<<0.001$; two-tailed paired $t$ test). $E$, Local infusion of S100B has no effect on the development of gamma oscillations in WT mice (mean \pm SEM; $n=7$ ). $\boldsymbol{F}$, Group comparison of the normalized gamma-band amplitude for before and after administration of KA in WT mice shows no effect of S100B infusion (mean \pm SEM).

where KA receptors are abundantly expressed (Wisden and Seeburg, 1993), and the principal neurons are recurrently connected. It is widely accepted that $\mathrm{GABA}_{\mathrm{A}}$ receptor-mediated transmission from local interneurons is important for generating the rhythm of the oscillations (Fisahn et al., 2004).

Hippocampal gamma oscillations were induced by systemic administration of KA $(10 \mathrm{mg} / \mathrm{kg})$. In agreement with our previous study (Sakatani et al., 2007), the gamma oscillations in hippocampal CA1 stratum radiatum started to develop in $10 \mathrm{~min}$ after the administration of KA. The amplitude of the gamma oscillations was significantly smaller in $S 100 B(-/-)$ animals at 45 min after KA injection than that in WT mice [WT, $n=9$; $\operatorname{S100B}(-/-), n=11$; gamma amplitude, PBS infusion period before KA injection, $p=0.12$; $45 \mathrm{~min}$ after KA injection, $p<$ 0.01] (Fig. 1A,B). The difference appeared from 19 to $60 \mathrm{~min}$ after KA injection (WT, $n=9 ; S 100 B(-/-), n=11$ ) (Fig. $1 C$ ). 
A

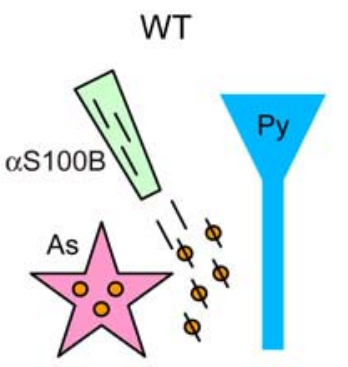

B

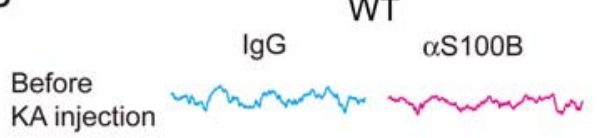

C
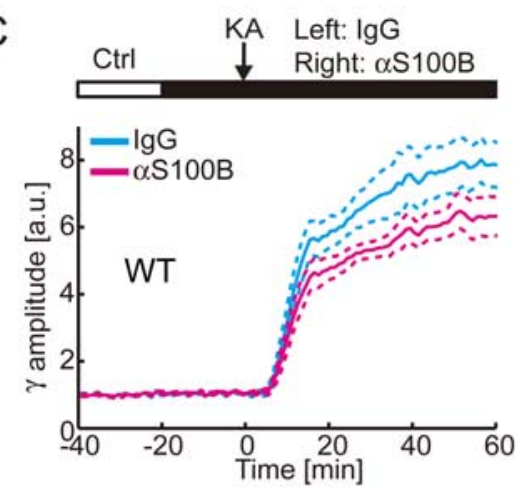

$\mathrm{E}$

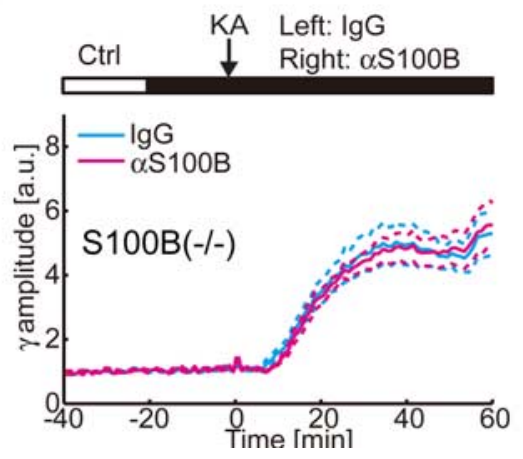

Before KA After KA

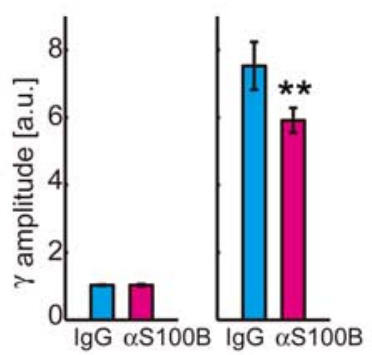

F

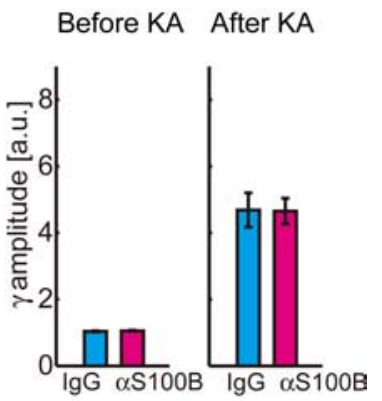

Figure 3. The functional blockade of endogenous extracellular S100B reduces KA-induced gamma oscillations in WT mice. $A$, Schematic diagram of the experiment. Function of endogenous extracellular S100B (orange particle) is blocked by applied antiS100B antibody (slash) in WT mice. As, Astrocyte; Py, pyramidal cell. $\boldsymbol{B}$, Representative traces of field potential recording shows that gamma oscillations in CA1 stratum radiatum after KA is smaller in anti-S100B $(0.2 \mathrm{mg} / \mathrm{ml})$ infusion side. C, Local infusion of anti-S100B antibody significantly decreases gamma-band amplitude from 10 to 60 min after KA injection in WT mice (mean \pm $\mathrm{SEM} ; n=8)$. $\boldsymbol{D}$, Group comparison of the normalized gamma-band amplitudes shows similar amplitudes in $0-10 \mathrm{~min}$ before KA injection (left) but decreased amplitudes in anti-S100B infusion side 40-50 min after KA injection in WT mice (right graph; mean $\pm S E M$; ${ }^{* *} p<0.01$; two-tailed paired $t$ test). $E$, Local infusion of anti-S100B antibody has no effect on the development of gamma oscillations in $\mathrm{STOOB}(-/-$ ) mice (mean $\pm \mathrm{SEM} ; n=7$ ). $\boldsymbol{F}$, Group comparison of the normalized gamma-band amplitude for before and after administration of KA in S100B (-/-) mice shows no effect of anti-S100B antibody (mean \pm SEM).

The power spectra from 30 to 50 min after KA injection showed that the gamma-band peak power of WT mice was significantly larger than that of $S 100 B(-/-)$ mice $[p<0.05$ at $40 \mathrm{~Hz}$; WT, $n=9 ; \operatorname{S100B}(-/-), n=11$ ] (Fig. $1 D)$.

To determine whether the modulation of the gamma oscillations is a direct effect of presence of extracellular S100B, we locally infused S100B protein in the CA1 region of $S 100 B(-/-)$ mice and examined the development of KA-induced gamma oscillations (Fig. 2A). Control measurements for pair-wise comparisons were simultaneously taken from the contralateral hippocampus. Local application of dimeric S100B by using a glass pipette containing $10 \mu \mathrm{M} \mathrm{S100B}$ resulted in a significantly larger amplitude of the gamma oscillations at $45 \mathrm{~min}$ after KA injection ( $n=8 ; p<0.001$; two-tailed paired $t$ test) (Fig. $2 B, D)$. The difference appeared from 8 to $60 \mathrm{~min}$ after KA injection $(n=8)$
(Fig. 2C). Postmortem immunohistochemistry against S100B shows that infused S100B was not taken up by astrocytes or neurons to a visible degree (supplemental figure, available at www.jneurosci.org as supplemental material). The result suggests that the extracellular presence of S100B plays a significant role in modulating the amplitude of KA-induced gamma oscillations. Similar experiments in WT animals exhibited no difference in gamma-band amplitude (Fig. $2 E, F)(n=$ 7; before KA injection, $p=0.18 ; 45 \mathrm{~min}$ after KA injection, $p=0.99$; two-tailed paired $t$ test), suggesting that the effect of extracellular S100B after KA is close to saturation.

Next, we applied anti-S100B antibody in WT mice to examine the effect of endogenous extracellular $\mathrm{S} 100 \mathrm{~B}$ on the gamma oscillations (Fig. $3 A$ ). Introduction of anti-S100B antibody before the systemic administration of KA significantly reduced the amplitude of the proceeding gamma oscillations at $45 \mathrm{~min}$ after KA injection $(n=8 ; p=0.01$; two-tailed paired $t$ test) (Fig. $3 B, D)$. The decrease continued from 10 to $60 \mathrm{~min}$ after KA injection $(n=$ 8) (Fig. 3C). Postmortem application of a fluorescent secondary antibody indicated that the anti-S100B antibody was not taken up by any cells (data not shown), thus further supporting a significant contribution of extracellular S100B in modulation of KA-induced gamma oscillations. As control, similar experiments were made with $S 100 B(-/-)$ mice, yielding no effect of infusion of the anti-S100B antibody (Fig. $3 E, F)(n=7$; before KA injection, $p=0.12 ; 45$ min after KA injection, $p=$ 0.95; two-tailed paired $t$ test). The result further supported the secretion of S100B in WT animals and specific effect of the antibody.

\section{Neural-activity-dependent S100B release}

Because $\mathrm{S} 100 \mathrm{~B}$ is known to be secreted from cultured astrocytes, we questioned if extracellular S100B concentration increased after KA administration. To investigate the global increase of extracellular S100B, CSF from the lateral ventricle was sampled at 45 and 75 min after the KA administration and ELISA against S100B protein was performed. The basal level of S100B protein was computed to be $3.0 \pm 1.9 \mathrm{ng} / \mathrm{ml}(n=$ 9) (Fig. 4), confirming the previous measurements of CSF S100B concentration (Oses et al., 2004; Yasuda et al., 2004). During KA-induced seizure, the concentration of CSF S100B did not significantly increase at $45 \mathrm{~min}(2.9 \pm 3.0 \mathrm{ng} / \mathrm{ml} ; n=9 ; p>0.9$; Tukey-Kramer test $)$ or $75 \mathrm{~min}(3.2 \pm 3.3 \mathrm{ng} / \mathrm{ml} ; n=12 ; p>0.9$; Tukey-Kramer test) after KA injection.

Although the CSF is an abundant source of intracranial fluid, it does not necessarily reflect the local concentration of extracellular S100B in the hippocampus, which is the focus of the KA- 


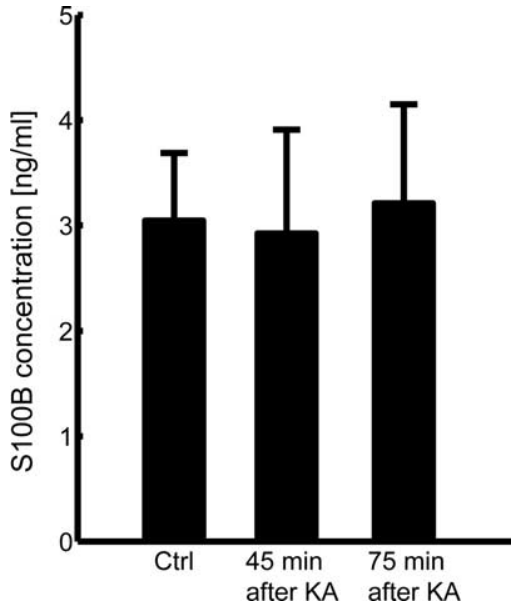

Figure 4. CSF S100B concentration in the lateral ventricle did not significantly increase after $K A$ injection $(10 \mathrm{mg} / \mathrm{kg}$, i.p.). Data are mean \pm SEM.

induced seizure. Therefore, we investigated S100B secretion using acute hippocampal slices. The concentration of released S100B in the bath solution $(500 \mu \mathrm{l})$ was measured to be $22 \pm 12$ $\mu \mathrm{g} / \mathrm{l}$ in control condition $(n=8)$. Assuming the relative volume of the extracellular space is 15\% (McBain et al., 1990) and the hippocampal sample volume is $1.5 \mu \mathrm{l}$, the basal extracellular S100B concentration in the hippocampus was estimated to be $49 \pm 27 \mathrm{ng} / \mathrm{ml}$. The extracellular S100B concentration after 30 min incubation in $400 \mathrm{nM} \mathrm{KA}$ was estimated to be $240 \pm 100$ $\mathrm{ng} / \mathrm{ml}(n=8)$. The estimate predicts that the local concentration of $\mathrm{S} 100 \mathrm{~B}$ after KA incubation is two orders of magnitude higher than CSF S100B. We conclude that acute administration of KA induces a local increase of extracellular S100B concentration in the hippocampus which is the main focus of KA-induced epilepsy but does not induce a global increase of S100B in CSF.

The S100B release after $30 \mathrm{~min} 400 \mathrm{~nm} \mathrm{KA}$ incubation was significantly larger than that of the control experiments $(570 \pm$ $290 \%$ from the corresponding control experiment level of $100 \%$; $n=8 ; p<0.001$ vs control; Tukey-Kramer test) (Fig. 5A). To address whether the $\mathrm{S} 100 \mathrm{~B}$ release is neural activity dependent, we blocked action potentials with $1 \mu \mathrm{M}$ TTX in the presence of $400 \mathrm{~nm}$ KA. The TTX incubation resulted in a significant reduction of extracellular S100B level $(140 \pm 140 \% ; n=7 ; p<0.001$ vs KA; Tukey-Kramer test). The result indicates that a significant proportion of the S100B release is neural activity dependent. Next, we questioned if S100B release from astrocytes are dependent on synaptic release of neurotransmitters. We applied the voltage-gated calcium channel blocker $\mathrm{Cd}$ to block action potential driven synaptic release of neurotransmitters. Cd $(100 \mu \mathrm{M})$ has blocked KA-induced S100B release ( $84 \pm 56 \%$; $n=9$; $p<0.001$ vs KA; Tukey-Kramer test). Next, we incubated hippocampal slices in a specific inhibitor of vacuolar $\mathrm{H}^{+}$-ATPase (V-ATPase), Baf for $2 \mathrm{~h}$ (Zhou et al., 2000) before KA incubation to inhibit both spontaneous and action potential driven neurotransmitter release from synaptic vesicles. The Baf treatment $(1 \mu \mathrm{M})$ blocked the KA-induced S100B release $(29 \pm 20 \% ; n=6 ; p<0.001$ vs KA; Tukey-Kramer test). These results indicate that presynaptic neurotransmitter release induces S100B secretion. To see if neurotransmitter release is sufficient to cause astrocytic secretion of S100B, we have prepared astrocyte primary culture and investigated the extracellular S100B level after application of glutamate, the most abundant neurotransmitter in the hippocampus. Treatment of astrocyte culture with $50 \mu \mathrm{M} \mathrm{L}$-glutamate resulted in a
A

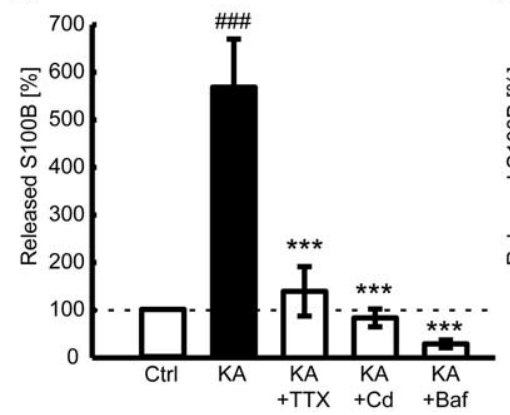

B

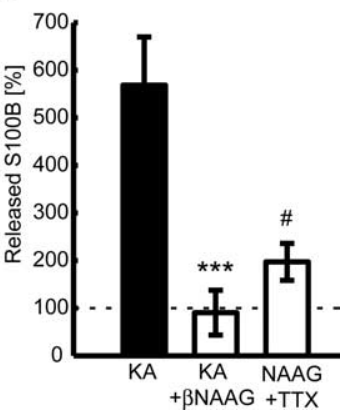

Figure 5. Neural-and synaptic-activity-dependent release of S100B is mediated by mGluR3. S100B secretion from hippocampal (HP) slices is quantified in the presence of various pharmacological reagents. The measured $S 100 B$ protein amounts are normalized to the corresponding control experiments. $A, K A(400 \mathrm{~nm})$ significantly increases $S 100 B$ release compared with con-

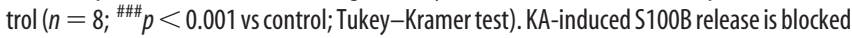
by the sodium channel blocker $\operatorname{TTX}(1 \mu \mathrm{m} ; n=7)$ and the calcium channel blocker $\mathrm{Cd}(100 \mu \mathrm{m}$; $n=9$ ). S100B secretion further drops below the control level by the V-ATPase blocker Baf (1 $\mu \mathrm{m} ; n=6$ ). $B$, KA-induced S100B release is blocked by mGluR3 antagonist $\beta$ NAAG (100 $\mu \mathrm{m}$; $n=5)$ in HP slices. Conversely, mGluR3 agonist NAAG $(200 \mu \mathrm{m})$ enhances S100B release without neural activity by TTX incubation ( $n=5$; ${ }^{\#} p<0.05$ vs control; two-tailed paired $t$ test). All data are mean \pm SEM; ${ }^{* * *} p<0.001$ vs KA; Tukey-Kramer test.

significant increase of extracellular S100B level $(130 \pm 19 \%$; $n=4 ; p<0.05$ vs control; two-tailed paired $t$ test).

A previous study reported that metabotropic glutamate receptor 3 (mGluR3) agonist induced S100B release in cultured astrocytes (Ciccarelli et al., 1999). To determine whether mGluR3 activation is essential for S100B release, we applied KA and the mGluR3 antagonist $\beta$ NAAG (Lea et al., 2001) to the hippocampal slices. $\beta$ NAAG $(100 \mu \mathrm{M})$ blocked the KA-induced S100B release $(91 \pm 110 \% ; n=5 ; p<0.001$ vs KA; Tukey-Kramer test) (Fig. 5B). Conversely, application of the mGluR3 agonist NAAG $(200 \mu \mathrm{M})$ resulted in a significant increase of extracellular S100B (200 $\pm 110 \% ; n=5 ; p<0.05$ vs control; two-tailed paired $t$ test). These results suggest that mGluR3 activation is critical to $\mathrm{S} 100 \mathrm{~B}$ release.

Next, we questioned if the release of S100B is mediated by astrocytic connexin 43 hemichannels. We examined the effect of the connexin mimetic peptide, Gap 26, which was known to be a connexin 43 hemichannel blocker (Chaytor et al., 1997). Surprisingly, Gap $26(100 \mu \mathrm{M})$ significantly enhanced the KA-induced S100B (3100 $\pm 1400 \% ; n=4 ; p<0.001$ vs KA; Tukey-Kramer test). The result suggests that $\mathrm{S} 100 \mathrm{~B}$ is not released through connexin 43 hemichannels of astrocytes (see Discussion).

\section{Involvement of RAGE activation by $\mathrm{S100B}$ in amplitude enhancement of KA-induced gamma oscillations}

S100B has been reported to work as a ligand for RAGE receptor family (Hofmann et al., 1999). We investigated if activation of RAGE is a component of kainate-induced gamma oscillations by measuring the local field potential in $R A G E(-/-)$ mice (Fig. 6). Similar to WT animals, the gamma oscillations appeared after systemic administration of $10 \mathrm{mg} / \mathrm{kg} \mathrm{KA} \mathrm{(Fig.} \mathrm{6A,C);} \mathrm{however,}$ the amplitude of the gamma-band local field potential was significantly attenuated in $R A G E(-/-)$ after KA administration $(n=$ $8 ; p<0.001$ ) (Fig. 6B,D). The gamma-band local field potential power did not differ in control condition $(p=0.34)$ (Fig. $6 B)$. To further test if RAGE activation by $\mathrm{S} 100 \mathrm{~B}$ is involved in the modulation of the gamma oscillations, we blocked the RAGE by applying mouse monoclonal anti-RAGE antibody $(0.2 \mathrm{mg} / \mathrm{ml})$ in WT mice and monitored the resulting development of KA- 
A

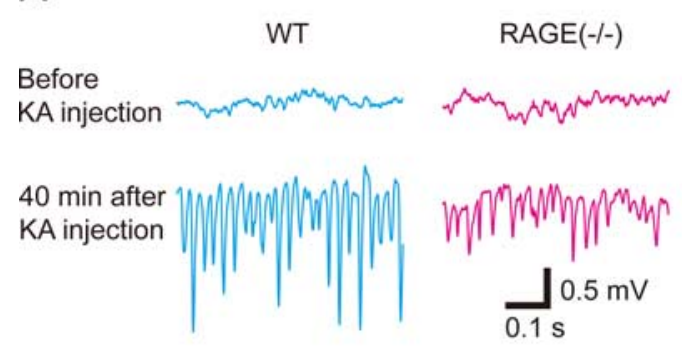

B

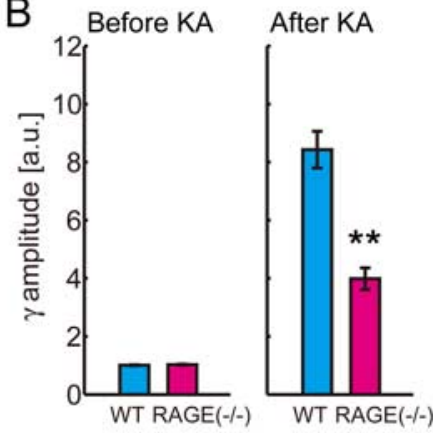

C

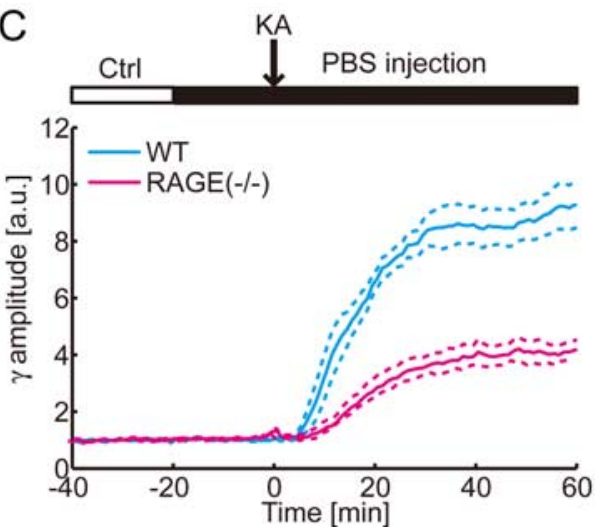

D

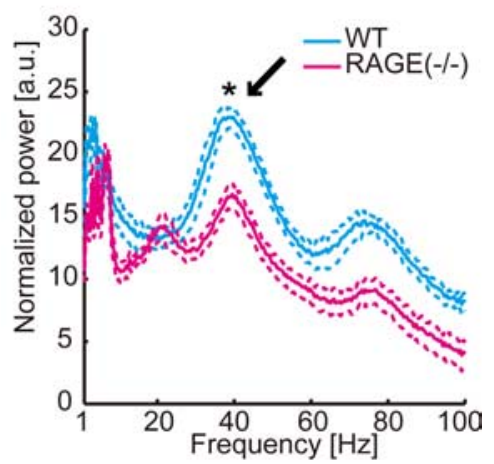

Figure 6. Power of KA-induced gamma-band activity at CA1 stratum radiatum is attenuated by deletion of RAGE. Traces for WT and $R A G E(-/-)$ are shown in blue and red, respectively. $A$, Representative traces show that gamma oscillations in CA1 stratum radiatum after KA injection are smaller in $\operatorname{RAGE}(-/-)$ animal. The traces are local field potential recordings in CA1 stratum radiatum. $\boldsymbol{B}$, Group comparison of the gamma-band $(30-80 \mathrm{~Hz})$ local field potential amplitudes shows similar amplitudes in 5-15 min before KA injection (left; mean \pm SEM; WT, $n=9 ; \operatorname{RAGE}(-/-), n=8 ; p=0.34$ ) but reduced amplitudes in RAGE (-/-) animals $40-50$ min after KA injection (right; mean \pm SEM; ${ }^{* *} p<0.001$ ). C, Time course of the gamma-band amplitude is plotted for WT and $R A G E(-/-)$ animals (mean \pm SEM). For each experiment, the gamma-band amplitude is normalized to the averaged magnitude during control period. D, Power spectra from 30 to 50 min after KA injection in WT and $R A G E(-/-$ ) animals (mean \pm SEM). Note that a gamma peak frequency is $\sim 40 \mathrm{~Hz}$ (arrow), which is significantly attenuated in $\operatorname{RAGE}(-/-)$ mice $\left({ }^{*} p<0.01\right)$.

induced gamma oscillations. Similar to the application of antiS100B antibody, the amplitude of KA-induced gamma oscillations decreased by the antibody blockade of RAGE $(n=7$; before KA injection, $p=0.43 ; 45 \mathrm{~min}$ after KA injection, $p<0.05$; two-tailed paired $t$ test) (Fig. 7A). Local infusion of the RAGE antibody in $R A G E(-/-)$ mice had no effect in KA-induced gamma oscillations ( $n=7$; before KA injection, $p=0.90 ; 45 \mathrm{~min}$ after KA injection, $p=0.43$; two-tailed paired $t$ test) (Fig. 7B). These results suggested that activation of RAGE has a role in enhancing the gamma oscillations.

As RAGE is known to be a multiligand receptor, it is possible that other ligands activated RAGE to modulate the gamma oscillations. To examine if S100B is an effective ligand for RAGE to modulate gamma oscillations, we performed the following two experiments. First, for negative control, we applied goat antiRAGE antibody $(0.2 \mathrm{mg} / \mathrm{ml})$, which was known to functionally block RAGE activation (Mitola et al., 2006), to $S 100 B(-/-)$ mice to check the effect of the antibody in the absence of extracellular S100B. In $S 100 B(-/-)$ mice, anti-RAGE antibody per se did not modulate the gamma oscillations ( $n=5$; before KA injection, $p=0.24 ; 45 \mathrm{~min}$ after KA injection, $p=0.78$; two-tailed paired $t$ test) (Fig. 7C). The result suggests that other ligands are not involved in the modulation of the gamma oscillations. Next, coapplication of S100B $(10 \mu \mathrm{M})$ and goat anti-RAGE antibody $(0.2$ $\mathrm{mg} / \mathrm{ml})$ in $S 100 B(-/-)$ mice abolished the effect of S100B on the gamma oscillations $(n=8$; before KA injection, $p>0.5$ for all pairs; 45 min after KA injection; IgG vs S100B, $p<0.01$; $\mathrm{S} 100 \mathrm{~B}$ vs $\mathrm{S} 100 \mathrm{~B}$ plus anti-RAGE antibody, $p<0.05$; Tukey's test) (Fig. 7D). The result shows that the antibody application is an effective means to functionally block RAGE in the presence of exogenous S100B. Together, these experiments demonstrate that $\mathrm{S} 100 \mathrm{~B}$ is the most potent ligand for RAGE that enhances the KAinduced gamma oscillations.

\section{Discussion}

KA-induced gamma oscillation amplitude is attenuated in $5100 B(-/-)$ animals in vivo (Sakatani et al., 2007). In the current study, we explored factors that contribute to the reduced gamma oscillations. We identified that the primary factor of the gamma oscillation reduction was the absence of extracellular S100B in knock-out animals. We observed that the release of S100B was neural activity dependent and that the release mechanism involves activation of mGluR3. Furthermore, we demonstrated that the S100B receptor RAGE plays a significant role in gamma oscillation modulation. Together, our findings provide the first physiological demonstration that extracellular S100B-mediated signaling is reflected in neural dynamics measured as local field potential in live animals (Fig. 8).

\section{Neural-activity-dependent release of S100B from astrocytes}

We attempted to determine whether the gamma oscillations were attributable to intracellular or extracellular presence of S100B. Our results show that extracellular presence of $\mathrm{S} 100 \mathrm{~B}$ is the primary factor that gives rise to the phenomena. The release mechanism and release sites of S100B have remained mostly unexplored in the context of neuron-glia communications. Detection of extracellular S100B by ELISA in acute hippocampal slices shows that S100B is indeed secreted after introduction of KA. A large part of the secretion is dependent on the presence of neuronal action potentials (Fig. 5). Although KA has some influence on electrophysiological membrane properties of astrocytes (Steinhäuser and Seifert, 2002), direct effect of KA on astrocytic release of S100B has been reported to be negligible (Tramontina et al., 2006). Our experiments with blockade of presynaptic transmitter release by $\mathrm{Cd}$ or Baf support that astrocytic S100B release is dependent on presynaptic release of neurotransmitter. Indeed, exposing astrocyte culture to glutamate was demonstrated to be sufficient to increase the $\mathrm{S} 100 \mathrm{~B}$ secretion.

Action potential dependent neurotransmitter release is blocked by $\mathrm{Cd}$, and Baf further inhibits spontaneous release of neurotransmitters. As a matter of fact, Baf application resulted in reduced $\mathrm{S} 100 \mathrm{~B}$ release in comparison with $\mathrm{Cd}$, which could be attributed to a contribution by spontaneous release of neurotransmitters. It should be noted, however, that Baf may also block vesicular release of substances from astrocytes (Araque et al., 
A

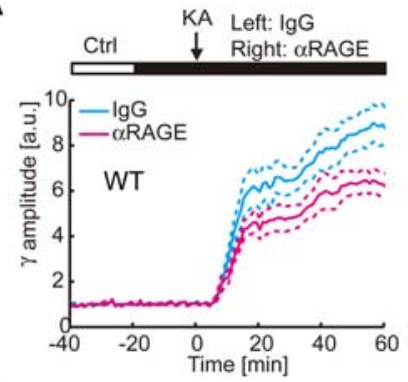

B

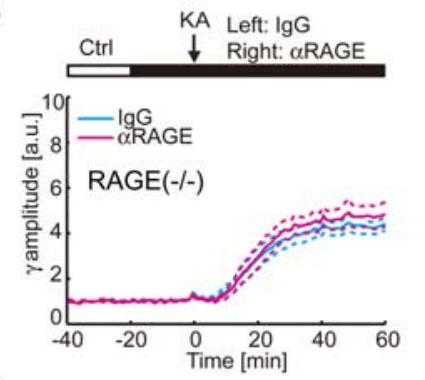

C
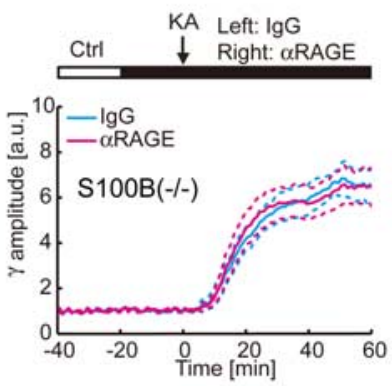

D

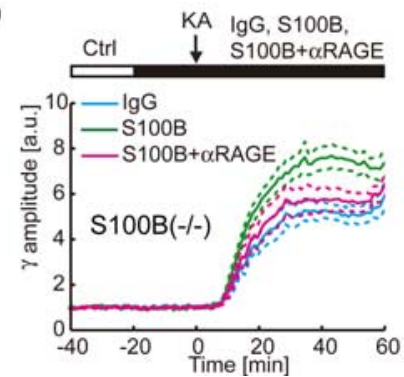

Before KA After KA

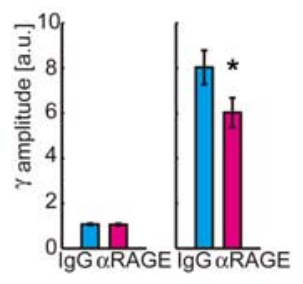

Before KA After KA

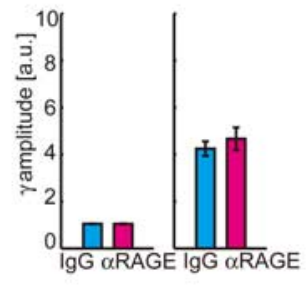

Before KA After KA

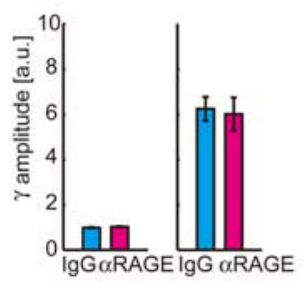

After KA

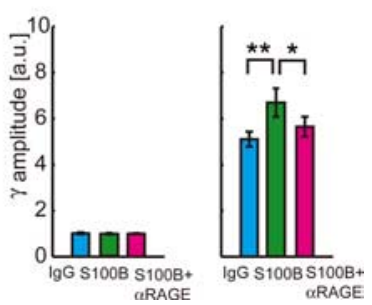

Figure 7. $S 100 B$ is an effective ligand of RAGE that enhances the gamma oscillations. $\boldsymbol{A}$, Time course of KA-induced gamma oscillation development (left) shows that local application of anti-RAGE antibody $(0.2 \mathrm{mg} / \mathrm{ml})$ in WT mice $(n=7)$ significantly attenuates the gamma oscillations. Group comparison of the normalized gamma-band amplitudes shows similar amplitudes in $0-10$ min before KA injection (center) but decreased amplitudes in anti-RAGE infusion side 40-50 min after KA injection (right graph; ${ }^{*} p<0.05$; two-tailed paired $t$ test). $\boldsymbol{B}$, Local application of anti-RAGE antibody $(0.2 \mathrm{mg} / \mathrm{ml})$ in $\operatorname{RAGE}(-/-)$ mice $(n=7)$ did not have a significantly effect on the amplitude of KA-induced gamma oscillations (before KA, 0-10 min before KA injection; after KA, 40 -50 min after KA injection). C, Local application of anti-RAGE antibody $(0.2 \mathrm{mg} / \mathrm{ml})$ in $5100 B(-/-)$ mice per se does not affect the amplitude of KA-induced gamma oscillations (left; $n=5$ ). Group comparison of the normalized gamma-band amplitudes shows similar amplitudes in both $0-10$ min before KA injection (center) and 40 -50 min after KA injection (right; two-tailed paired ttest). D, Coapplication of S100B $(10 \mu \mathrm{m})$ and anti-RAGE antibody $(0.2 \mathrm{mg} / \mathrm{ml})$ in S100B (-/-) mice abolished the effect of S100B on the gamma amplitude (left; $n=8$ for all cases). Group comparison of the normalized gamma-band amplitudes shows similar amplitudes in $0-10$ min before KA injection (center; $p>0.5$ for all pairs; Tukey test). The enhanced gamma amplitude by $S 100 B$ is inhibited by anti-RAGE antibody in $40-50$ min after KA injection (right graph; ${ }^{*} p<0.05,{ }^{* *} p<0.01$; Tukey's test). All the plots and bars are represented as mean \pm SEM.

2000). Therefore, although circumstantial evidence supports that S100B release is likely to be synaptic activity dependent, our experiments also suggests a possibility that S100B release from astrocytes may be vesicular release.

As the gamma oscillation reduction is most pronounced in stratum radiatum (Sakatani et al., 2007), and glutamate is the major transmitter in stratum radiatum, we asked a possible influence of mGluR3 activation, which has been previously reported to play a role in $\mathrm{S100B}$ release in dissociated astrocyte culture (Ciccarelli et al., 1999). Our data further confirm the significant role of mGluR3 activation in S100B release in preserved neuronglia circuitry. Previous immunohistochemical studies reported abundance of mGluR3 in cortical and hippocampal glial cells (Ohishi et al., 1993; Tanabe et al., 1993; Petralia et al., 1996). The molecular cascades that mediates S100B release upon the activation of astrocytic mGluR3 remains to be explored, but a previous study reported a close association of mGluR3 and aquaporin 4 water channels (Shigemoto et al., 1999), which suggests a possible volume change of astrocytes as a consequence of mGluR3 activation. Increased levels of S100B have been reported in epileptic patients (Griffin et al., 1995) and experimental animals after seizures (Oses et al., 2004). It is conceivable that glutamate spills over the synaptic cleft during seizures and activates mGluR3s in peri-synaptic astrocytic processes, resulting in a facilitation of S100B release. Interestingly, mGluR2 and 3 are highly expressed in hippocampal astrocytes of patients with temporal lobe epilepsy (Tang and Lee, 2001) and are known to be upregulated in animals with kainate model of temporal lobe epilepsy (Aronica et al., 2000; Ferraguti et al., 2001).

\section{Cx43 in S100B secretion}

Release mechanism of S100B from astrocytes remains unclear to date. One of the potential release mechanisms is through the astrocytic hemichannel $\mathrm{Cx} 43$, which is known to be permeable to relatively large molecules compared with other connexin hemichannel family (Sáez et al., 2003; Harris, 2007). Surprisingly, the blockade of astrocyte dominant $\mathrm{Cx} 43$ hemichannels by Gap 26 resulted in a drastic enhancement of KA-induced S100B release. The result indicates that the $\mathrm{Cx} 43$ hemichannels have inhibitory effects on S100B secretion. Among gliotransmitters, ATP has been known to be released from astrocytic connexin hemichannels (Stout et al., 2002). Extracellular ATP is hydrolyzed and dephosphorylated to adenosine, resulting in a reduction of transmitter release frequency from presynaptic terminals (Scholz and Miller, 1992). Such a presynaptic inhibitory mechanism of glutamate through the astrocytic hemichannel release of ATP can explain the inhibitory effect of $\mathrm{Cx} 43$ hemichannels on S100B secretion. Regardless of the mechanism for the enhancement of S100B secretion by Cx 43 blockade, our data clearly show that the release of $\mathrm{S} 100 \mathrm{~B}$ is not mediated by $\mathrm{Cx} 43$ hemichannels. In human monocytes, interleukin-1-like or classical vesicular release of S100 protein has been shown to be negative, yet protein kinase $\mathrm{C}$ activation and microtubule network has been demonstrated to be involved in S100 release (Rammes et al., 1997).

\section{Potential role of RAGE in gamma oscillation amplitude modulation}

S100B has been reported to be a ligand for RAGE among other known ligands including advanced glycation end products, amyloid $\beta$ peptide, $\beta$-sheet fibrils, amphoterin (HMGB-1), and S100 family proteins (Hofmann et al., 1999). As both genetic deletion of RAGE (Fig. 6) and antibody blockade against RAGE (Fig. 7A) resulted in a decrease of gamma oscillation amplitude, a possible interaction of released S100B with the RAGE was demonstrated. Subsequent experiments with $S 100 B(-/-)$ animals showed that $\mathrm{S} 100 \mathrm{~B}$ is the most significant ligand of the RAGE for the gamma oscillation modulation (Fig. 7C,D). The dissociation constant of 


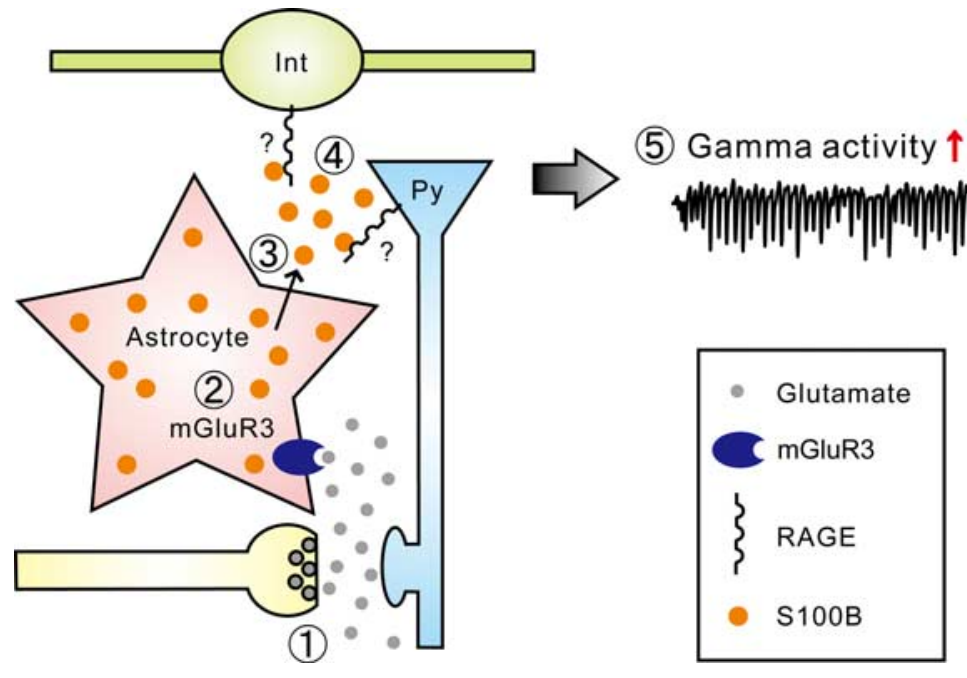

Figure 8. Schematic representation of the proposed S100B signaling. The basal level of extracellular S100B is low in the hippocampus. The neural activity is increased upon administration of KA which increases the release of glutamate from presynaptic terminals (1) by action potentials mediated calcium influx and direct activation of kainate receptors. The excess amount of synaptically released glutamate activates astrocytic mGluR3 (2). As a result, S100B is released from the astrocyte to the extracellular space (3) by a mechanism independent of Cx43 hemichannels. The extracellular S100B binds to RAGE (4) which in turn enhances the gamma oscillation amplitude (5). The localization of RAGE remains to be determined. Py, Pyramidal cell; Int, interneuron.

RAGE for S100B was reported to be $11 \mathrm{~nm}$ (Leclerc et al., 2007); therefore, only a small portion of RAGE is activated at rest because $\mathrm{S} 100 \mathrm{~B}$ concentration in the hippocampus is estimated to be of $1 \mathrm{~nm}$ order. However, KA incubation increased the extracellular S100B concentration to $\sim 10 \mathrm{nM}$, which activates almost half of available RAGE. Such large-scale activation of RAGE conceivably has a significant contribution to the enhancement of the gamma oscillations, although the exact pathway that links biochemical activation of RAGE to physiological function of synapses remains to be identified. As the gamma amplitude difference appears within an hour, it is unlikely that RAGE is synthesized de novo and transported to the membrane surface. The putative RAGE is likely to be expressed on membrane surface or internalized receptors are exposed to the surface upon KA application. A previous in situ hybridization study reported high expression levels of RAGE mRNA in rat CA1 pyramidal cells that underwent moderate hypoxic insult and absence of mRNA in the untreated hippocampus (Ma et al., 2003). Recently, RAGE mRNA was detected in mouse brain (Myint et al., 2006), and RAGE proteins were biochemically detected in gliosome as well as synaptosome fractions prepared from mouse hippocampus (Pedrazzi et al., 2006). Further cell-type specific knock-out mice of RAGE will help to unravel function sites and downstream mechanisms of S100B-RAGE interaction in the gamma oscillations.

Literature suggests that extracellular presence of S100B helps neuronal cell survival (Huttunen et al., 2000; Leclerc et al., 2007). It is conceivable that neural-activity-dependent release of S100B has a protective role for neural survival in neuropathological conditions. Indeed, increased levels of S100B have been reported in various neuropathological conditions including epilepsy (Griffin et al., 1995), Alzheimer's disease (Van Eldik and Griffin, 1994), and schizophrenia (Lara et al., 2001; Rothermundt et al., 2001). Further investigations at the cellular and synaptic level are needed to directly assess the effect of extracellular S100B on membrane properties.

In conclusion, our results suggest $\mathrm{S} 100 \mathrm{~B}$ acts as a neuromodulatory protein that is released from astrocytes in a neural- and synaptic-activity-dependent manner in vivo. It is widely acknowl- edged that neuron-glia communications occur via amino acids or purines (Nedergaard et al., 2002; Haydon and Carmignoto, 2006). To our knowledge, this is the first demonstration that a small molecular weight protein, such as $\mathrm{S100B}$, functions as a gliotransmitter. The mGluR3-mediated release of S100B protein and the subsequent activation of RAGE add another pathway to the neuron-glia communications.

\section{References}

Araque A, Li N, Doyle RT, Haydon PG (2000) SNARE protein-dependent glutamate release from astrocytes. J Neurosci 20:666-673.

Aronica E, van Vliet EA, Mayboroda OA, Troost D, da Silva FH, Gorter JA (2000) Upregulation of metabotropic glutamate receptor subtype mGluR3 and mGluR5 in reactive astrocytes in a rat model of mesial temporal lobe epilepsy. Eur J Neurosci 12:2333-2344.

Bartos M, Vida I, Jonas P (2007) Synaptic mechanisms of synchronized gamma oscillations in inhibitory interneuron networks. Nat Rev Neurosci 8:45-56.

Carninci P, Kasukawa T, Katayama S, Gough J, Frith MC, Maeda N, Oyama R, Ravasi T, Lenhard B, Wells C, Kodzius R, Shimokawa K, Bajic VB, Brenner SE, Batalov S, Forrest AR, Zavolan M, Davis MJ, Wilming LG, Aidinis V, et al. (2005) The transcriptional landscape of the mammalian genome. Science 309:1559-1563.

Chaytor AT, Evans WH, Griffith TM (1997) Peptides homologous to extracellular loop motifs of connexin 43 reversibly abolish rhythmic contractile activity in rabbit arteries. J Physiol 503:99-110.

Ciccarelli R, Di Iorio P, Bruno V, Battaglia G, D'Alimonte I, D’Onofrio M, Nicoletti F, Caciagli F (1999) Activation of A(1) adenosine or mGlu3 metabotropic glutamate receptors enhances the release of nerve growth factor and S-100beta protein from cultured astrocytes. Glia 27:275-281.

Donato R (2003) Intracellular and extracellular roles of S100 proteins. Microsc Res Tech 60:540-551.

Engel AK, Singer W (2001) Temporal binding and the neural correlates of sensory awareness. Trends Cogn Sci 5:16-25.

Ferraguti F, Corti C, Valerio E, Mion S, Xuereb J (2001) Activated astrocytes in areas of kainate-induced neuronal injury upregulate the expression of the metabotropic glutamate receptors 2/3 and 5. Exp Brain Res 137:1-11.

Fisahn A, Contractor A, Traub RD, Buhl EH, Heinemann SF, McBain CJ (2004) Distinct roles for the kainate receptor subunits GluR5 and GluR6 in kainate-induced hippocampal gamma oscillations. J Neurosci 24:9658-9668.

Gerlai R, Wojtowicz JM, Marks A, Roder J (1995) Overexpression of a calcium-binding protein, $\mathrm{S} 100$ beta, in astrocytes alters synaptic plasticity and impairs spatial learning in transgenic mice. Learn Mem 2:26-39.

Gloveli T, Dugladze T, Rotstein HG, Traub RD, Monyer H, Heinemann U, Whittington MA, Kopell NJ (2005) Orthogonal arrangement of rhythm-generating microcircuits in the hippocampus. Proc Natl Acad Sci U S A 102:13295-13300.

Gray CM, König P, Engel AK, Singer W (1989) Oscillatory responses in cat visual cortex exhibit inter-columnar synchronization which reflects global stimulus properties. Nature 338:334-337.

Griffin WS, Stanley LC, Ling C, White L, MacLeod V, Perrot LJ, White CL 3rd, Araoz C (1989) Brain interleukin 1 and S-100 immunoreactivity are elevated in Down syndrome and Alzheimer disease. Proc Natl Acad Sci U S A 86:7611-7615.

Griffin WS, Yeralan O, Sheng JG, Boop FA, Mrak RE, Rovnaghi CR, Burnett BA, Feoktistova A, Van Eldik LJ (1995) Overexpression of the neurotrophic cytokine S100 beta in human temporal lobe epilepsy. J Neurochem 65:228-233.

Harris AL (2007) Connexin channel permeability to cytoplasmic molecules. Prog Biophys Mol Biol 94:120-143. 
Haydon PG, Carmignoto G (2006) Astrocyte control of synaptic transmission and neurovascular coupling. Physiol Rev 86:1009-1031.

Hofmann MA, Drury S, Fu C, Qu W, Taguchi A, Lu Y, Avila C, Kambham N, Bierhaus A, Nawroth P, Neurath MF, Slattery T, Beach D, McClary J, Nagashima M, Morser J, Stern D, Schmidt AM (1999) RAGE mediates a novel proinflammatory axis: a central cell surface receptor for S100/calgranulin polypeptides. Cell 97:889-901.

Huttunen HJ, Fages C, Rauvala H (1999) Receptor for advanced glycation end products (RAGE)-mediated neurite outgrowth and activation of NFkappaB require the cytoplasmic domain of the receptor but different downstream signaling pathways. J Biol Chem 274:19919-19924.

Huttunen HJ, Kuja-Panula J, Sorci G, Agneletti AL, Donato R, Rauvala H (2000) Coregulation of neurite outgrowth and cell survival by amphoterin and S100 proteins through receptor for advanced glycation end products (RAGE) activation. J Biol Chem 275:40096-40105.

Kettenmann H, Ransom BR, eds (2005) Neuroglia. Ed 2. New York: Oxford UP.

Kligman D, Marshak DR (1985) Purification and characterization of a neurite extension factor from bovine brain. Proc Natl Acad Sci U S A 82:7136-7139.

Lara DR, Gama CS, Belmonte-de-Abreu P, Portela LV, Gonçalves CA, Fonseca M, Hauck S, Souza DO (2001) Increased serum S100B protein in schizophrenia: a study in medication-free patients. J Psychiatr Res 35:11-14.

Lea PM 4th, Wroblewska B, Sarvey JM, Neale JH (2001) beta-NAAG rescues LTP from blockade by NAAG in rat dentate gyrus via the type 3 metabotropic glutamate receptor. J Neurophysiol 85:1097-1106.

Leclerc E, Fritz G, Weibel M, Heizmann CW, Galichet A (2007) S100B and S100A6 differentially modulate cell survival by interacting with distinct RAGE (receptor for advanced glycation end products) immunoglobulin domains. J Biol Chem 282:31317-31331.

Ma L, Carter RJ, Morton AJ, Nicholson LF (2003) RAGE is expressed in pyramidal cells of the hippocampus following moderate hypoxicischemic brain injury in rats. Brain Res 966:167-174.

McBain CJ, Traynelis SF, Dingledine R (1990) Regional variation of extracellular space in the hippocampus. Science 249:674-677.

Mitola S, Belleri M, Urbinati C, Coltrini D, Sparatore B, Pedrazzi M, Melloni E, Presta M (2006) Cutting edge: extracellular high mobility group box-1 protein is a proangiogenic cytokine. J Immunol 176:12-15.

Montgomery SM, Buzsáki G (2007) Gamma oscillations dynamically couple hippocampal CA3 and CA1 regions during memory task performance. Proc Natl Acad Sci U S A 104:14495-14500.

Myint KM, Yamamoto Y, Doi T, Kato I, Harashima A, Yonekura H, Watanabe T, Shinohara H, Takeuchi M, Tsuneyama K, Hashimoto N, Asano M, Takasawa S, Okamoto H, Yamamoto H (2006) RAGE control of diabetic nephropathy in a mouse model: effects of RAGE gene disruption and administration of low-molecular weight heparin. Diabetes 55:2510-2522.

Nedergaard M, Takano T, Hansen AJ (2002) Beyond the role of glutamate as a neurotransmitter. Nat Rev Neurosci 3:748-755.

Newman EA (2003) New roles for astrocytes: regulation of synaptic transmission. Trends Neurosci 26:536-542.

Nishiyama H, Knopfel T, Endo S, Itohara S (2002) Glial protein S100B modulates long-term neuronal synaptic plasticity. Proc Natl Acad Sci U S A 99:4037-4042.

Ohishi H, Shigemoto R, Nakanishi S, Mizuno N (1993) Distribution of the mRNA for a metabotropic glutamate receptor (mGluR3) in the rat brain: an in situ hybridization study. J Comp Neurol 335:252-266.

Oses JP, Leke R, Portela LV, Lara DR, Schmidt AP, Casali EA, Wofchuk S, Souza DO, Sarkis JJ (2004) Biochemical brain markers and purinergic parameters in rat CSF after seizure induced by pentylenetetrazol. Brain Res Bull 64:237-242.

Pedrazzi M, Raiteri L, Bonanno G, Patrone M, Ledda S, Passalacqua M, Milanese M, Melloni E, Raiteri M, Pontremoli S, Sparatore B (2006) Stimulation of excitatory amino acid release from adult mouse brain glia subcellular particles by high mobility group box 1 protein. J Neurochem 99:827-838.

Petralia RS, Wang YX, Niedzielski AS, Wenthold RJ (1996) The metabotropic glutamate receptors, mGluR2 and mGluR3, show unique postsynaptic, presynaptic and glial localizations. Neuroscience 71:949-976.

Rammes A, Roth J, Goebeler M, Klempt M, Hartmann M, Sorg C (1997) Myeloid-related protein (MRP) 8 and MRP14, calcium-binding proteins of the S100 family, are secreted by activated monocytes via a novel, tubulin-dependent pathway. J Biol Chem 272:9496-9502.
Rothermundt M, Missler U, Arolt V, Peters M, Leadbeater J, Wiesmann M, Rudolf S, Wandinger KP, Kirchner H (2001) Increased S100B blood levels in unmedicated and treated schizophrenic patients are correlated with negative symptomatology. Mol Psychiatry 6:445-449.

Rothermundt M, Falkai P, Ponath G, Abel S, Bürkle H, Diedrich M, Hetzel G, Peters M, Siegmund A, Pedersen A, Maier W, Schramm J, Suslow T, Ohrmann P, Arolt V (2004) Glial cell dysfunction in schizophrenia indicated by increased S100B in the CSF. Mol Psychiatry 9:897-899.

Sáez JC, Contreras JE, Bukauskas FF, Retamal MA, Bennett MV (2003) Gap junction hemichannels in astrocytes of the CNS. Acta Physiol Scand 179:9-22.

Sakatani S, Seto-Ohshima A, Itohara S, Hirase H (2007) Impact of S100B on local field potential patterns in anesthetized and kainic acid-induced seizure conditions in vivo. Eur J Neurosci 25:1144-1154.

Schmitt A, Bertsch T, Henning U, Tost H, Klimke A, Henn FA, Falkai P (2005) Increased serum S100B in elderly, chronic schizophrenic patients: negative correlation with deficit symptoms. Schizophr Res 80:305-313.

Scholz KP, Miller RJ (1992) Inhibition of quantal transmitter release in the absence of calcium influx by a $\mathrm{G}$ protein-linked adenosine receptor at hippocampal synapses. Neuron 8:1139-1150.

Selinfreund RH, Barger SW, Pledger WJ, Van Eldik LJ (1991) Neurotrophic protein S100 beta stimulates glial cell proliferation. Proc Natl Acad Sci U S A 88:3554-3558.

Sen J, Belli A (2007) S100B in neuropathologic states: the CRP of the brain? J Neurosci Res 85:1373-1380.

Shashoua VE, Hesse GW, Moore BW (1984) Proteins of the brain extracellular fluid: evidence for release of S-100 protein. J Neurochem 42:1536-1541.

Shigemoto R, Masugi M, Fujimoto K (1999) Assembly-disassembly of metabotropic glutamate receptor 3 and water channel aquaporin 4 in astrocyte cell membrane. Neuropharmacology 38:A42-a42.

Sorci G, Riuzzi F, Agneletti AL, Marchetti C, Donato R (2004) S100B causes apoptosis in a myoblast cell line in a RAGE-independent manner. J Cell Physiol 199:274-283.

Steinhäuser C, Seifert G (2002) Glial membrane channels and receptors in epilepsy: impact for generation and spread of seizure activity. Eur J Pharmacol 447:227-237.

Stout CE, Costantin JL, Naus CC, Charles AC (2002) Intercellular calcium signaling in astrocytes via ATP release through connexin hemichannels. J Biol Chem 277:10482-10488.

Tanabe Y, Nomura A, Masu M, Shigemoto R, Mizuno N, Nakanishi S (1993) Signal transduction, pharmacological properties, and expression patterns of two rat metabotropic glutamate receptors, mGluR3 and mGluR4. J Neurosci 13:1372-1378.

Tang FR, Lee WL (2001) Expression of the group II and III metabotropic glutamate receptors in the hippocampus of patients with mesial temporal lobe epilepsy. J Neurocytol 30:137-143.

Tramontina F, Tramontina AC, Souza DF, Leite MC, Gottfried C, Souza DO, Wofchuk ST, Gonçalves CA (2006) Glutamate uptake is stimulated by extracellular S100B in hippocampal astrocytes. Cell Mol Neurobiol 26:81-86.

Van Eldik LJ, Griffin WS (1994) S100 beta expression in Alzheimer's disease: relation to neuropathology in brain regions. Biochim Biophys Acta 1223:398-403.

Van Eldik LJ, Zimmer DB (1987) Secretion of S-100 from rat C6 glioma cells. Brain Res 436:367-370.

Volterra A, Meldolesi J (2005) Astrocytes, from brain glue to communication elements: the revolution continues. Nat Rev Neurosci 6:626-640.

Wisden W, Seeburg PH (1993) A complex mosaic of high-affinity kainate receptors in rat brain. J Neurosci 13:3582-3598.

Xiong Z, O’Hanlon D, Becker LE, Roder J, MacDonald JF, Marks A (2000) Enhanced calcium transients in glial cells in neonatal cerebellar cultures derived from S100B null mice. Exp Cell Res 257:281-289.

Yasuda Y, Tateishi N, Shimoda T, Satoh S, Ogitani E, Fujita S (2004) Relationship between S100beta and GFAP expression in astrocytes during infarction and glial scar formation after mild transient ischemia. Brain Res 1021:20-31.

Zhou Q, Petersen CC, Nicoll RA (2000) Effects of reduced vesicular filling on synaptic transmission in rat hippocampal neurones. J Physiol 525:195-206.

Zimmer DB, Cornwall EH, Landar A, Song W (1995) The S100 protein family: history, function, and expression. Brain Res Bull 37:417-429. 